\title{
Ursolic acid induces apoptosis via Akt/NF-кB signaling suppression in T24 human bladder cancer cells
}

\author{
LONG GAI $^{1,2}, \mathrm{NACAI}^{3}$, LINGLING WANG ${ }^{4,5}, \mathrm{XIAOYI} \mathrm{XU}^{6}$ and XIANGBO KONG ${ }^{1}$ \\ ${ }^{1}$ Department of Urologic Surgery, China-Japan Union Hospital of Jilin University, Changchun, Jilin 130033; \\ ${ }^{2}$ Department of Urologic Surgery, Heilongjiang Province Hospital, Harbin; ${ }^{3}$ Department of Respiratory Medicine, \\ Haerbin No.1 Hospital, Harbin, Heilongjiang 150000; ${ }^{4}$ Department of Neurology, The First Hospital of Jilin University; \\ ${ }^{5}$ Department of Neurology, the Affiliated Hospital of Beihua University; ${ }^{6}$ Department of Hematology and Oncology, \\ The First Hospital of Jilin University, Changchun, Jilin 130021, P.R. China
}

Received November 8, 2012; Accepted February 27, 2013

DOI: $10.3892 / \mathrm{mmr} .2013 .1364$

\begin{abstract}
The Akt/NF- $\mathrm{B}$ pathway is involved in numerous anti-apoptotic and drug resistance events which occur in various types of bladder cancer. The present study investigated the role of ursolic acid in the regulation of anti-apoptotic Akt and NF- $\kappa$ Bp65 signaling. T24 human bladder cancer cells were treated with ursolic acid at final concentrations of 12.5, 25 or $50 \mu \mathrm{mol} / 1$ for $48 \mathrm{~h}$. Quantitative PCR (qPCR) and western blotting were performed to detect mRNA and protein expression, respectively. The results showed that anti-apoptotic phosphoAkt1 (pAkt1), phospho-IкB $\alpha(\mathrm{pI} \kappa \mathrm{B} \alpha), \mathrm{NF}-\kappa \mathrm{Bp} 65$ and $\mathrm{Bcl}-2$ were inhibited and pro-apoptotic caspase-3 was upregulated in a dose-dependent manner. A $50 \mu \mathrm{mol} / 1$ dose of ursonic acid decreased the mRNA expression levels of anti-apoptotic NF- $\kappa B p 65$ and Bcl-20.17 (8.9/52.6)-fold and 0.22 (9.5/42.3)-fold, respectively. The pro-apoptotic caspase-3 mRNA expression levels were upregulated 4.78 (38.7/8.1)-fold. The anti-apoptotic pAkt1, pI $\kappa \mathrm{B} \alpha, \mathrm{NF}-\kappa \mathrm{Bp} 65$ and $\mathrm{Bcl}-2$ protein levels were downregulated to 5.1 (blot grayscales vs. control at 32.3), 3.2 (vs. 24.2), 8.5 (vs. 45.1) and 9.2 (vs. 40.3). The protein levels of pro-apoptotic caspase-3 were upregulated to 20.7 (vs. 4.7). The proliferative activity of T24 cells treated with 12.5, 25.0 and $50.0 \mu \mathrm{mol} / 1$ ursolic acid was significantly reduced compared with that of control cells $(83.8,56.2$ and 31.5 vs. $97.6 \%$, respectively, $\mathrm{P}<0.05$ for each). In conclusion, ursolic acid is important in inducing apoptosis via the suppression of $\mathrm{Akt} / \mathrm{NF}-\kappa \mathrm{B}$ signaling in T24 human bladder cancer cells and this occurs in a dose-dependent manner. Ursolic acid may therefore serve as a naturally occurring candidate drug for the prevention and treatment of bladder cancer.
\end{abstract}

Correspondence to: Professor Xiangbo Kong, Department of Urologic Surgery, China-Japan Union Hospital of Jilin University, 126 Xiantai Street, Changchun, Jilin 130033, P.R. China

E-mail: gailong2000@sina.com

Key words: ursolic acid, bladder cancer, apoptosis, signaling, Akt, $\mathrm{NF}-\kappa \mathrm{B}$

\section{Introduction}

Ursolic acid, a naturally occurring triterpenoid, induces the apoptosis of human cancer cells through multiple signaling pathways (1-10). In studies on the pro-apoptotic role of ursolic acid in urinary system cancer, prostate cancer cells are usually targeted and the apoptotic signaling pathways have been shown to be activated by ursolic acid. Kassi et al (11) demonstrated that ursolic acid downregulates $\mathrm{Bcl}-2$ and promotes apoptosis in PC-3 human hormone refractory prostate cancer and androgen-sensitive LNCaP cells. Zhang et al (12) showed that ursolic acid induces the apoptosis of PC-3 cells, in which Bcl-2 phosphorylation, Fas overexpression and caspase- 8 and -9 activation were detected, through activation of the JNK pathway and inhibition of the Akt pathway in a dose-dependent manner. Shanmugam et al (13) revealed that ursolic acid inhibits the NF- $\mathrm{B}$ and STAT3 cell survival pathways in the DU145 and LNCaP prostate cancer cell lines, which suppresses the growth of prostate cancer xenografts in nude mice. Limami et al (14) demonstrated that the P2Y2/Src/ p38/COX-2 pathway is involved in the resistance to ursolic acid-induced apoptosis in prostate cancer cells (14).

Bladder cancer is a type of urinary cancer. Two recent studies demonstrated the pro-apoptotic role of ursolic acid in bladder cancer cells. Tu et al (15) reported that ursolic acid derivatives increase the levels of reactive oxygen species (ROS) and induce apoptosis in NTUB1 human urothelial cancer cells. Zheng et al (16) showed that ursolic acid activates AMP-activated protein kinase (AMPK), which induces the apoptosis of T24 human bladder cancer cells.

Bladder cancer cells also overexpress multiple anti- apoptotic and drug-resistant signals. Sun et al (17) demonstrated that the PI3K/Akt/mTOR pathway correlates with tumor progression and poor survival times in patients with urothelial bladder cancer. Plissonnier et al (18) reported that TNF-related apoptosis-inducing ligand (TRAIL) is upregulated by the antidiabetic drug ciglitazone and induces apoptosis in high-grade bladder cancer cells. Jayasooriya et al (19) showed that a methanol extract of Hydroclathrus clathratus downregulates the TNF- $\alpha$ - 
induced phosphorylation of PI3K/Akt and mitogen-activated protein kinase (MAPK) and suppresses matrix metalloproteinase-9 (MMP9) in T24 bladder cancer cells. A study by Kunze et al (20) revealed that bladder cancer cells overexpress anti-apoptotic Bcl-2, Bcl-xL and XIAP, while survivin and the use of siRNA knock them down. Chen et al (21) reported that the ERK/JNK-AP1 pathways are activated by 2-aminobiphenyl (21). Yu et al (22) showed that the ROS-modulated apoptotic pathways in TSGH-8301 human bladder cancer cells are triggered by norcantharidin and this is accompanied by the downregulation of FasL, Bax, Bid, cytochrome $c$ and caspase-3,-8 and -9. Lee et al (23) reported that interleukin-28A triggers the wound healing migration of bladder cancer cells via NF- $\kappa$ B-mediated MMP-9 expression, which induces the upregulation of the MAPK pathway. Takeuchi et al (24) reported that the phosphorylation of ERK1/2 is involved in chemotherapy-resistance in bladder cancer and that sunitinib may be used to suppress ERK1/2 phosphorylation to enhance the antitumor effects. According to Huang et al (25), the downregulation of cyclin D, CDK4, cyclin E, CDK2, phospho-Rb, phospho-Akt and Bcl-2 and the simultaneous upregulation of cytochrome $c$, Apaf-1, AIF, caspase-3, -7 and -9 and Bax protein expression and caspase activity occurs in T24 cells following bufalin treatment.

Therefore, we hypothesized that ursolic acid is important in promoting the apoptosis of bladder cancer cells via the suppression of the Akt and NF- $\mathrm{BB}$ signaling pathways. In the present study, ursolic acid was used to treat bladder cancer cells to investigate its role in the apoptotic signaling pathways.

\section{Materials and methods}

Materials. Ursolic acid (purity, >90\%) was purchased from Sigma-Aldrich (Aldrich U6753; Shanghai, China). The total protein extraction and TRIzol total RNA extraction kits were purchased from Invitrogen (Carlsbad, CA,

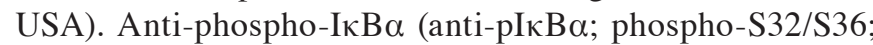
sc-8404), anti-NF-кBp65 (sc-8008), anti-Bcl-2 (sc-509) and anti-caspase-3 (sc-7272) antibodies were purchased from Santa Cruz Biotechnology, Inc. (Santa Cruz, CA, USA). Anti-phospho-Akt1 (anti-pAkt1; phospho-T308; ab105731) and anti-glyceraldehyde 3-phosphate dehydrogenase (anti-GAPDH; ab8245) monoclonal mouse antibodies were obtained from Abcam (Beijing, China). Horseradish peroxidase (HRP)-labeled goat anti-mouse secondary antibody was purchased from Abcam. 3-(4,5-dimethylthiazol-2-yl)2,5diphenyltetrazolium bromide (MTT) was purchased from Sigma (St. Louis, MO, USA). The Moloney Murine Leukemia Virus Reverse Transcriptase (M-MLV RTase) kit was purchased from Promega (Beijing, China). The 2X SYBR real-time PCR kit was obtained from Roche (Shanghai, China). The bicinchoninic acid (BCA) protein detection kit and the enhanced chemiluminescence (ECL) detection kit were purchased from Pierce Chemicals, Thermo Fisher Scientific Inc. (Rockford, IL, USA).

Cell line. The T24 human urinary bladder cancer (transitional cell carcinoma) cell line was purchased from the American Type Culture Collection (ATCC; no. HTB-4; Manassas, VA, USA). The cells were cultured in Dulbecco's modified Eagle's medium (DMEM) containing 10\% fetal bovine serum (FBS) (Invitrogen, Gibco, Carlsbad, CA, USA) in a 5\% $\mathrm{CO}_{2}$ incubator and were passaged with a $0.25 \%$ trypsin (Sigma) $/ 0.03 \%$ EDTA solution.

Treatment. T24 cells were digested, suspended and seeded in each well of 6-well plates at a density of $1.0 \times 10^{6} / \mathrm{ml}$ in $2 \mathrm{ml}$ of complete culture medium. The cells were cultured for $24 \mathrm{~h}$ and exposed to ursolic acid for $48 \mathrm{~h}$. Ursolic acid was dissolved in anhydrous ethanol, then added to the cells at final concentrations of $12.5,25$ or $50 \mu \mathrm{mol} / 1$. An equivalent amount of ethanol was added to the cells as a control.

Quantitative PCR ( $q P C R)$. T24 cells were harvested and total RNA was extracted with the total RNA extraction kit using the TRIzol method. First-strand cDNA was synthesized using M-MLV RTase according to the manufacturer's instructions and real-time PCR was performed using the cDNA template according to the manufacturer's instructions. The amplification of GAPDH was used as an internal control in each reaction system. The reaction conditions were as follows: 40 cycles of $95^{\circ} \mathrm{C}$ for $30 \mathrm{sec}, 58^{\circ} \mathrm{C}$ for $60 \mathrm{sec}$ and $72^{\circ} \mathrm{C}$ for $60 \mathrm{sec}$. The primers were designed based on the GenBank sequence using Beacon Designer 7 (Premier Biosoft, Palo Alto, CA, USA) and the primer sequences were verified using Blast (26). Primer synthesis and DNA sequencing were performed by Shanghai Sangon Biotechnology (Shanghai, China). The primer sequences were as follows: NF- $\kappa \mathrm{Bp} 65$ sense, 5'-GCAAAGGAAACGCCAGAAGC-3' and antisense, 5'-CACTACCGAACATGCCTCCAC-3'; Bcl-2 sense, 5'-ATGACTTCTCTCGTCGCTACT-3' and antisense, 5'-CCCATCCCTGAAGAGTTCCGA-3'; caspase-3 sense, 5'-CATGGCCTGTCAGAAAATAC-3' and antisense, 5'-TAACCCGAGTAAGAATGTGC-3'; and GAPDH (housekeeping gene) sense, 5'-AATGTGTCCGTCGTGGATCTG-3' and antisense, 5'-CAACCTGGTCCTCAGTGTAGC-3'.

Western blotting. Western blotting was used to detect the protein expression levels of pAkt1, $\mathrm{pI} \kappa \mathrm{B} \alpha, \mathrm{NF}-\kappa \mathrm{Bp} 65, \mathrm{Bcl}-2$ and caspase-3. The T24 cells were harvested and cell lysis was performed using the eukaryotic cell lysis buffer according to the manufacturer's instructions, followed by extraction of the total protein. Protein quantity was determined using the BCA method. For each sample $(30 \mu \mathrm{g})$, proteins were separated by $12 \%$ SDS-PAGE and blotted with a wet transfer device (BioRad Laboratories, Inc., Shanghai, China) onto nitrocellulose membranes. The membranes were then immersed in a blocking solution containing $10 \%$ skimmed milk in PBS Tween-20 (PBST), followed by agitation for $1 \mathrm{~h}$. After washing three times with Tris-buffered saline Tween-20 (TBST) for 5 min each time, the membranes were immersed in the primary antibody at a dilution of 1:1,000 with the blocking solution at room temperature and then agitated for $1 \mathrm{~h}$. After washing, the membranes were incubated in the HRP-labeled secondary antibody at a dilution of 1:10,000 with the blocking solution at room temperature and then agitated for $1 \mathrm{~h}$. After an additional rinse, the membranes underwent color development using the ECL method, followed by X-film photography. GAPDH protein was used as an internal control. The grayscale values (total raw density) of blots were measured using the VisionWorksLS 
analysis software available in the UVP EC3 (600) Imaging System (Ultra-Violet Products, Upland, CA, USA).

MTT assay. The medium was refreshed to discard the ursolic acid. The cells were supplemented with $20 \mu \mathrm{l}$ MTT solution $(5 \mathrm{mg} / \mathrm{ml})$, followed by incubation in a $\mathrm{CO}_{2}$ incubator for $4 \mathrm{~h}$. The supernatant was discarded and $100 \mu \mathrm{l}$ dimethylsulfoxide (DMSO; Sigma) was applied to each well. When the purple crystals at the bottom of the well were completely dissolved, the absorbance value was measured with a Thermo Multiskan MK3 microplate reader (Thermo Fisher Scientific Inc., Waltham, MA, USA) at a wavelength of $\lambda=490 \mathrm{~nm}$. Cell viability (\%) was calculated as experimental absorbance/normal absorbance x 100.

Statistical analysis. Data are expressed as the mean \pm standard deviation (SD). The statistical software SPSS10.0 was used for statistical analysis. Paired comparisons were performed using the Student's t-test. $\mathrm{P}<0.05$ was considered to indicate a statistically significant difference.

\section{Results}

Detection of mRNA levels using $q P C R$. The expression of cell signaling molecules detected using qPCR are shown in Fig. 1. Prior to ursolic acid treatment, the control cells expressed high mRNA levels of anti-apoptotic NF- $\kappa$ Bp65 and Bcl-2 and a low level of pro-apoptotic caspase-3 mRNA. As increasing concentrations of ursolic acid were applied $(12.5,25.0$ and $50.0 \mu \mathrm{mol} / \mathrm{l})$, the anti-apoptotic signaling was inhibited and pro-apoptotic signaling was activated. Antiapoptotic NF-кBp65 levels decreased 0.74 (38.9/52.6), 0.35 (18.6/52.6) and 0.17 (8.9/52.6)-fold, respectively; and Bcl-2 levels decreased 0.77 (32.6/42.3), 0.50 (21.3/42.3) and 0.22 (9.5/42.3)-fold, respectively. Pro-apoptotic caspase-3 levels increased 1.63 (13.2/8.1), 2.53 (20.5/8.1), 4.78 (38.7/8.1)-fold, respectively. The pro-apoptotic induction triggered by ursolic acid occurred in a dose-dependent manner.

Detection of protein levels using western blotting. Fig. 2 shows the expression of the cell signaling molecules, detected using western blotting. Prior to treatment with ursolic acid, high levels of anti-apoptotic pAkt1, $\mathrm{pI} \kappa \mathrm{B} \alpha, \mathrm{NF}-\kappa \mathrm{Bp} 65$ and $\mathrm{Bcl}-2$ and low levels of pro-apoptotic caspase-3 were expressed in the control cells. With the application of increasing concentrations of ursolic acid $(12.5,25.0$ and $50.0 \mu \mathrm{mol} / 1)$, all the anti-apoptotic signaling was inhibited (Fig. 2A), while the pro-apoptotic signaling was upregulated (Fig. 2B).

Table I shows the complete grayscales of the blots presented in Fig. 2, demonstrating the total levels of the proteins detected. The blot grayscales for the anti-apoptotic pAkt1 protein were 26.6, 10.4 and 5.1 vs. 32.3; for $\mathrm{pI} \kappa \mathrm{B} \alpha$ were $17.3,8.8$ and 3.2 vs. 24.2; for pNF- $\mathrm{Bp} 65$ were 32.2, 21.2 and 8.5 vs. 45.1; for Bcl-2 were 33.6, 19.7 and 9.2 vs. 40.3; and for pro-apoptotic caspase-3 protein were $6.1,11.6$ and 20.7 vs. 4.7, respectively (12.5, 25.0 and $50.0 \mu \mathrm{mol} / 1 \mathrm{ursolic}$ acid vs. control). The pro-apoptotic induction triggered by ursolic acid treatment occurred in a dose-dependent manner.

Cell proliferation. Fig. 3 shows the cell viability after $48 \mathrm{~h}$ of treatment with ursolic acid. The proliferative activity of
Table I. Relative grayscales of blots (48 h, \%/GAPDH).

\begin{tabular}{|c|c|c|c|c|}
\hline \multirow[b]{2}{*}{ Protein blots } & \multirow[b]{2}{*}{ Control } & \multicolumn{3}{|c|}{$\begin{array}{l}\text { Ursolic acid doses } \\
\qquad(\mu \mathrm{mol} / \mathrm{l})\end{array}$} \\
\hline & & 12.5 & 25.0 & 50.0 \\
\hline GAPDH (37 kDa) & 104.5 & 100.0 & 99.3 & 100.2 \\
\hline pAkt1 (56 kDa) & 32.3 & 26.6 & 10.4 & 5.1 \\
\hline $\mathrm{pI} \kappa \mathrm{B} \alpha(40 \mathrm{kDa})$ & 24.2 & 17.3 & 8.8 & 3.2 \\
\hline NF-кBp65 (65 kDa) & 45.1 & 32.2 & 21.2 & 8.5 \\
\hline Bcl-2 (30 kDa) & 40.3 & 33.6 & 19.7 & 9.2 \\
\hline Caspase-3 (34 kDa) & 4.7 & 6.1 & 11.6 & 20.7 \\
\hline
\end{tabular}

GAPDH, glyceraldehyde 3-phosphate dehydrogenase; p, phospho-.
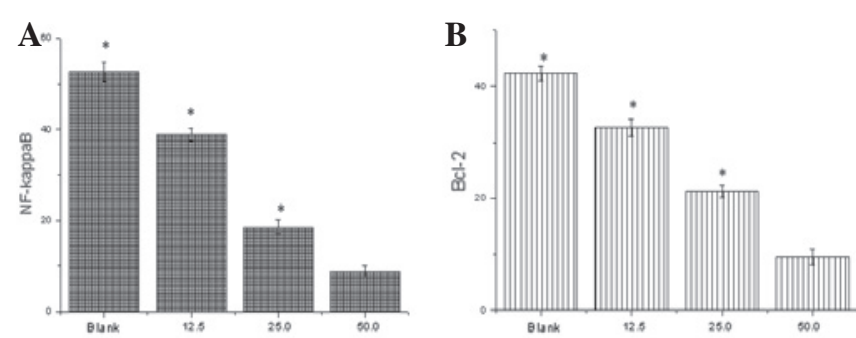

C

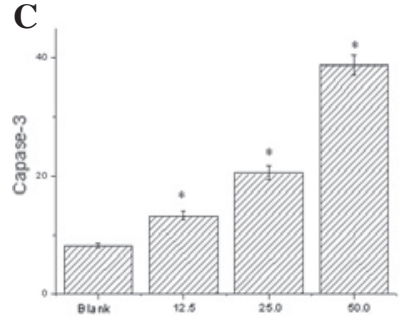

D

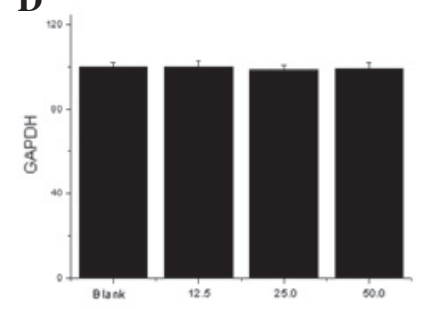

Figure 1. Relative mRNA levels (\%) vs. GAPDH (dRn). The doses of ursolic acid used were $12.5,25.0$ and $50.0 \mu \mathrm{mol} / 1$. As the concentration of ursolic acid was increased, anti-apoptotic signaling was inhibited and pro-apoptotic signaling was activated. With $50.0 \mu \mathrm{mol} / 1 \mathrm{ursolic}$ acid, the anti-apoptotic NF-кBp65 and Bcl-2 decreased 0.17 (8.9/52.6)-fold and 0.22 (9.5/42.3)-fold, respectively and pro-apoptotic caspase-3 was upregulated 4.78 (38.7/8.1)fold. ${ }^{*} \mathrm{P}<0.05$ compared with the control $(\mathrm{n}=3)$. Blank, control cells; GAPDH, glyceraldehyde 3-phosphate dehydrogenase (housekeeping gene).

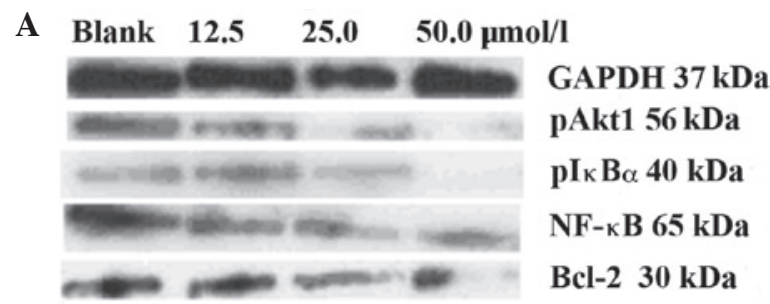

B Blank $12.5 \quad 25.0 \quad 50.0 \mu \mathrm{mol} / \mathrm{l}$

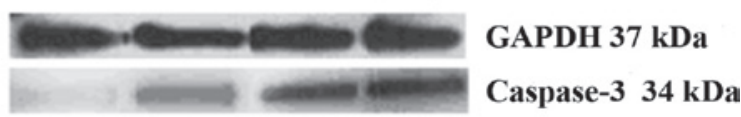

Figure 2. Western blotting results for (A) anti-apoptotic and (B) pro-apoptotic proteins after $48 \mathrm{~h}$ of treatment with ursolic acid. The doses of ursolic acid used were 12.5, 25.0 and $50.0 \mu \mathrm{mol} / 1$. Blank, control cells; GAPDH, glyceraldehyde 3-phosphate dehydrogenase (housekeeping gene); p, phospho-. 


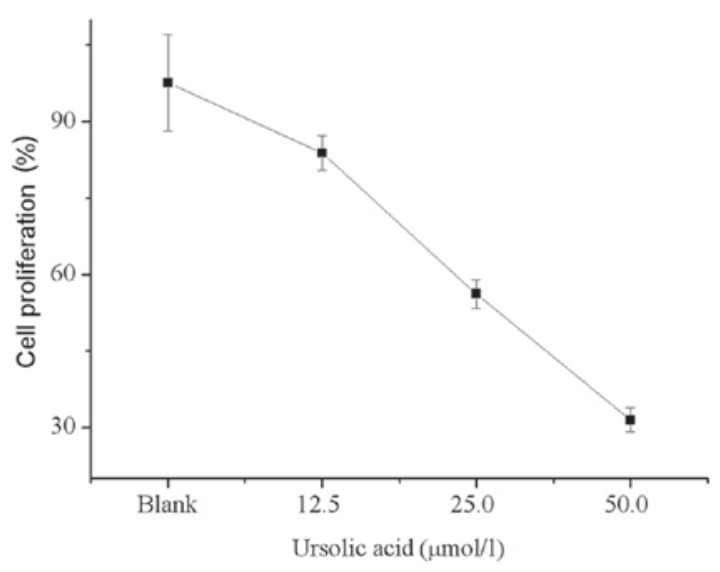

Figure 3. Cell proliferation of T24 bladder cancer cells treated with ursolic acid for $48 \mathrm{~h}$. The doses of ursolic acid used were 12.5, 25.0 and $50.0 \mu \mathrm{mol} / 1$. Blank, control cells. ${ }^{*} \mathrm{P}<0.05$ compared with the control $(\mathrm{n}=3)$.

T24 cells treated with $12.5,25.0$ and $50.0 \mu \mathrm{mol} / 1$ ursolic acid decreased and was significantly lower compared with that of the control cells $(83.8,56.2,31.5$ vs. $97.6 \%$, respectively; $\mathrm{P}<0.05$ for each). The antitumor effect of ursolic acid treatment occurred in a dose-dependant manner.

\section{Discussion}

The Akt/NF-kB pathways are involved in numerous anti-apoptotic and drug-resistant events, which occur in various types of bladder cancer $(17,19,23,25)$. Inhibition of the Akt/NF- $\mathrm{KB}$ pathways results in the downregulation of Bcl-2 with a simultaneous upregulation of caspase-3 $(20,22,25)$. In the present study, ursolic acid was used to treat T24 bladder cancer cells. qPCR and western blotting were performed to investigate the role of ursolic acid in altering the levels of anti-apoptotic pAkt, $\mathrm{pI \kappa B} \alpha, \mathrm{pNF}-\kappa \mathrm{Bp} 65$ and Bcl-2 and pro-apoptotic caspase-3.

Prior to the treatment with ursolic acid, Akt1 phosphorylation at threonine 308 was overexpressed in the control cells (26). The hyperactivated pAkt1 exhibited a serine-threonine protein kinase activity and triggered the cascade enzymes, resulting in an increased phosphorylation of IкB $\alpha$ at serines 32 and 36 . $\mathrm{pI} \kappa \mathrm{B} \alpha$ was disassociated from NF- $\kappa \mathrm{B}$, resulting in increased NF- $\kappa$ Bp 65 at the mRNA and protein levels. The hyperactivated pAkt1 also triggered an overexpression of anti-apoptotic Bcl-2 at the mRNA and protein levels, which contributed to the sustained proliferation of the control cells.

By contrast, the use of ursolic acid led to a significant decrease in pAkt1 and $\mathrm{pI} \kappa \mathrm{B} \alpha$ and in the NF- $\mathrm{kBp} 65 \mathrm{mRNA}$ and protein levels. The downregulation of pAkt1 indicates that the serine-threonine protein kinase activity of Akt was weakened. Subsequently, the phosphorylation of IкB $\alpha$ was downregulated to a level that caused the the release of NF- $\mathrm{KB}$ to be repressed, resulting in a decrease in NF- $\kappa B p 65$ levels. The decreased serine-threonine protein kinase activity of Akt also resulted in the downregulation of anti-apoptotic Bcl-2; thus, suppression of T24 cell apoptosis was reduced.

The downregulation of pAkt1 and NF-kBp65 indicates that the signal amplification and transduction pathways were efficiently inhibited. Accordingly, the pro-apoptotic caspase-3 mRNA and protein levels were significantly upregulated. As previously reported, the upregulated caspase-3 decreases IKK2 levels $(27,28)$ in necrotized or apoptotic cancer cells, which decreases I $\kappa \mathrm{B} \alpha$ phosphorylation and leads to a reduced NF- $\kappa$ Bp65 level. The upregulated caspase-3 also directly decreases the NF- $\kappa B p 65$ protein level $(27,29)$, resulting in a secondary downregulation of NF- $\mathrm{kp} 65$ in apoptotic cancer cells. The present study demonstrated that NF-кBp65 signaling was markedly downregulated in T24 cells. The apoptotic T24 cells showed a decrease in proliferation. The MTT assay results revealed that the proliferation of T24 cells was significantly inhibited by ursolic acid. Additionally, the pro-apoptotic induction triggered by ursolic acid occured in a dose-dependent manner.

In conclusion, ursolic acid is important in the induction of apoptosis via AKT/NF- $\mathrm{KB}$ signaling suppression in T24 human bladder cancer cells and this occurs in a dose-dependent manner. Thus, Akt and NF- $\mathrm{kB}$ are potential targets for bladder cancer therapy and ursolic acid may serve as a naturally-occurring candidate drug for the prevention and treatment of bladder cancer.

\section{Acknowledgements}

This study was funded by the National Natural Science Foundation of China (no. 81172270/H1617).

\section{References}

1. Achiwa Y, Hasegawa K, Komiya T and Udagawa Y: Ursolic acid induces Bax-dependent apoptosis through the caspase-3 pathway in endometrial cancer SNG-II cells. Oncol Rep 13: 51-57, 2005.

2. Kim KH, Seo HS, Choi HS, Choi I, Shin YC and Ko SG: Induction of apoptotic cell death by ursolic acid through mitochondrial death pathway and extrinsic death receptor pathway in MDA-MB-231 cells. Arch Pharm Res 34: 1363-1372, 2011.

3. Manu KA and Kuttan G: Ursolic acid induces apoptosis by activating $\mathrm{p} 53$ and caspase-3 gene expressions and suppressing NF-kappaB mediated activation of bcl-2 in B16F-10 melanoma cells. Int Immunopharmacol 8: 974-981, 2008.

4. Liu JJ, Liu WD, Yang HZ, Zhang Y, Fang ZG, Liu PQ, Lin DJ, Xiao RZ, Hu Y, Wang CZ, Li XD, He Y and Huang RW: Inactivation of PI3k/Akt signaling pathway and activation of caspase-3 are involved in tanshinone I-induced apoptosis in myeloid leukemia cells in vitro. Ann Hematol 89: 1089-1097, 2010.

5. Li J, Liang X and Yang X: Ursolic acid inhibits growth and induces apoptosis in gemcitabine-resistant human pancreatic cancer via the JNK and PI3K/Akt/NF- $\kappa \mathrm{B}$ pathways. Oncol Rep 28: 501-510, 2012.

6. Shishodia S, Majumdar S, Banerjee S and Aggarwal BB: Ursolic acid inhibits nuclear factor-kappaB activation induced by carcinogenic agents through suppression of IkappaBalpha kinase and p65 phosphorylation: correlation with down-regulation of cyclooxygenase 2, matrix metalloproteinase 9, and cyclin D1. Cancer Res 63: 4375-4383, 2003.

7. Tang C, Lu YH, Xie JH, Wang F, Zou JN, Yang JS, Xing YY and Xi T: Downregulation of survivin and activation of caspase-3 through the PI3K/Akt pathway in ursolic acid-induced HepG2 cell apoptosis. Anticancer Drugs 20: 249-258, 2009.

8. Wu B, Wang X, Chi ZF, Hu R, Zhang R, Yang W and Liu ZG: Ursolic acid-induced apoptosis in K562 cells involving upregulation of PTEN gene expression and inactivation of the PI3K/Akt pathway. Arch Pharm Res 35: 543-548, 2012.

9. Wang J, Li Y, Wang X and Jiang C: Ursolic acid inhibits proliferation and induces apoptosis in human glioblastoma cell lines U251 by suppressing TGF- $\beta 1 / \mathrm{miR}-21 /$ PDCD4 pathway. Basic Clin Pharmacol Toxicol 111: 106-112, 2012.

10. Wang JS, Ren TN and Xi T: Ursolic acid induces apoptosis by suppressing the expression of FoxM1 in MCF-7 human breast cancer cells. Med Oncol 29: 10-15, 2012. 
11. Kassi E, Papoutsi Z, Pratsinis H, Aligiannis N, Manoussakis M and Moutsatsou P: Ursolic acid, a naturally occurring triterpenoid, demonstrates anticancer activity on human prostate cancer cells. J Cancer Res Clin Oncol 133: 493-500, 2007.

12. Zhang Y, Kong C, Zeng Y, Wang L, Li Z, Wang H, Xu C and Sun Y: Ursolic acid induces PC-3 cell apoptosis via activation of JNK and inhibition of Akt pathways in vitro. Mol Carcinog 49: 374-385, 2010

13. Shanmugam MK, Rajendran P, Li F, Nema T, Vali S, Abbasi T, Kapoor S, Sharma A, Kumar AP, Ho PC, Hui KM and Sethi G: Ursolic acid inhibits multiple cell survival pathways leading to suppression of growth of prostate cancer xenograft in nude mice. J Mol Med (Berl) 89: 713-727, 2011

14. Limami Y, Pinon A, Leger DY, Pinault E, Delage C, Beney tout JL, Simon A and Liagre B: The $\mathrm{P} 2 \mathrm{Y} 2 / \mathrm{Src} / \mathrm{p} 38 / \mathrm{COX}-2$ pathway is involved in the resistance to ursolic acid-induced apoptosis in colorectal and prostate cancer cells. Biochimie 94: 1754-1763, 2012.

15. Tu HY, Huang AM, Wei BL, Gan KH, Hour TC, Yang SC, Pu YS and Lin CN: Ursolic acid derivatives induce cell cycle arrest and apoptosis in NTUB1 cells associated with reactive oxygen species. Bioorg Med Chem 17: 7265-7274, 2009.

16. Zheng QY, Jin FS, Yao C, Zhang T, Zhang GH and Ai X: Ursolic acid-induced AMP-activated protein kinase (AMPK) activation contributes to growth inhibition and apoptosis in human bladder cancer T24 cells. Biochem Biophys Res Commun 419: 741-747, 2012.

17. Sun CH, Chang YH and Pan CC: Activation of the PI3K/Akt/ mTOR pathway correlates with tumour progression and reduced survival in patients with urothelial carcinoma of the urinary bladder. Histopathology 58: 1054-1063, 2011.

18. Plissonnier ML, Fauconnet S, Bittard $\mathrm{H}$ and Lascombe I: The antidiabetic drug ciglitazone induces high grade bladder cancer cells apoptosis through the up-regulation of TRAIL. PLoS One 6: e28354, 2011.

19. Jayasooriya RG, Choi YH, Moon SK, Kim WJ and Kim GY: Methanol extract of Hydroclathrus clathratus suppresses matrix metalloproteinase-9 in T24 bladder carcinoma cells by suppressing the NF- $\kappa \mathrm{B}$ and MAPK pathways. Oncol Rep 27: 541-546, 2012

20. Kunze D, Kraemer K, Erdmann K, Froehner M, Wirth MP and Fuessel S: Simultaneous siRNA-mediated knockdown of antiapoptotic BCL2, Bcl-xL, XIAP and survivin in bladder cancer cells. Int J Oncol: Jul 6, 2012 (Epub ahead of print). doi: 10.3892/ ijo.2012.1549)
21. Chen CC, Cheng YY, Chen SC, Tuan YF, Chen YJ, Chen CY and Chen LC: Cyclooxygenase-2 expression is up-regulated by 2-aminobiphenyl in a ROS and MAPK-dependent signaling pathway in a bladder cancer cell line. Chem Res Toxicol 25: 695-705, 2012.

22. Yu CC, Ko FY, Yu CS, Lin CC, Huang YP, Yang JS, Lin JP and Chung JG: Norcantharidin triggers cell death and DNA damage through S-phase arrest and ROS-modulated apoptotic pathways in TSGH 8301 human urinary bladder carcinoma cells. Int J Oncol 41: 1050-1060, 2012.

23. Lee SJ, Lim JH, Choi YH, Kim WJ and Moon SK: Interleukin-28A triggers wound healing migration of bladder cancer cells via NF- $\kappa$ B-mediated MMP-9 expression inducing the MAPK pathway. Cell Signal 24: 1734-1742, 2012.

24. Takeuchi A, Eto M, Shiota M, Tatsugami K, Yokomizo A, Kuroiwa K, Itsumi M and Naito S: Sunitinib enhances antitumor effects against chemotherapy-resistant bladder cancer through suppression of ERK1/2 phosphorylation. Int J Oncol 40: 1691-1696, 2012.

25. Huang WW, Yang JS, Pai SJ, Wu PP, Chang SJ, Chueh FS, Fan MJ, Chiou SM, Kuo HM, Yeh CC, Chen PY, Tsuzuki M and Chung JG: Bufalin induces $\mathrm{G}(0) / \mathrm{G}(1)$ phase arrest through inhibiting the levels of cyclin D, cyclin E, CDK2 and CDK4, and triggers apoptosis via mitochondrial signaling pathway in T24 human bladder cancer cells. Mutat Res 732: 26-33, 2012.

26. Weizhong Z, Shuohui G, Hanjiao Q, Yuhong M, Xiaohua Y, Jian $C$ and Lisen L: Inhibition of cytohesin-1 by siRNA leads to reduced IGFR signaling in prostate cancer. Braz J Med Biol Res 44: 642-646, 2011.

27. Barkett M and Gilmore TD: Control of apoptosis by Rel/NF- $\kappa \mathrm{B}$ transcription factors. Oncogene 18: 6910-6924, 1999.

28. Tang $G$, Yang J, Minemoto $Y$ and Lin A: Blocking caspase-3-mediated proteolysis of IKKbeta suppresses TNF-alpha-induced apoptosis. Mol Cell 8: 1005-1016, 2001

29. Ravi R, Mookerjee B, van Hensbergen Y, Bedi GC, Giordano A, El-Deiry WS, Fuchs EJ and Bedi A: p53-mediated repression of nuclear factor-kappaB RelA via the transcriptional integrator p300. Cancer Res 58: 4531-4536, 1998. 